\title{
Communicating incidental and reportable findings from research MRIs: considering factors beyond the findings in an underrepresented pediatric population
}

\author{
Kiley B. Vander Wyst ${ }^{1,2}$, Micah L. Olson 2,3, Smita S. Bailey ${ }^{4}$, Ana Martinez Valencia², Armando Peña², \\ Jeffrey Miller ${ }^{4}$, Mitchell Shub ${ }^{5,6}$, Lee Seabrooke ${ }^{7}$, Janiel Pimentel ${ }^{3}$, Kiri Olsen ${ }^{3,7}$, Robert B. Rosenberg ${ }^{7,8}$ and \\ Gabriel Q. Shaibi ${ }^{2,3,9^{*}}$
}

\begin{abstract}
Background: The application of advanced imaging in pediatric research trials introduces the challenge of how to effectively handle and communicate incidental and reportable findings. This challenge is amplified in underserved populations that experience disparities in access to healthcare as recommendations for follow-up care may be difficult to coordinate. Therefore, the purpose of the present report is to describe the process for identifying and communicating findings from a research MRI to low-income Latino children and families.

Methods: Latino adolescents ( $n=86$ ) aged 12-16years old with obesity and prediabetes underwent a research MRI (3 Tesla Philips Ingenia ${ }^{\circledR}$ ) as part of a randomized controlled diabetes prevention trial. The research MRIs were performed at baseline and 6 months to assess changes in whole-abdominal fat distribution and organ fat in response to the intervention. An institutional pathway was developed for identifying and reporting findings to participants and families. The pathway was developed through a collaborative process with hospital administration, research compliance, radiology, and the research team. All research images were reviewed by a board-certified pediatric radiologist who conveyed findings to the study pediatrician for determination of clinical actionability and reportability to children and families. Pediatric sub-specialists were consulted as necessary and a primary care practitioner (PCP) from a free community health clinic agreed to receive referrals for uninsured participants.
\end{abstract}

Results: A total of 139 images (86 pre- and 53 post-intervention) were reviewed with 31 findings identified and 23 deemed clinically actionable and reportable. The only reportable finding was severely elevated liver fat (> 10\%, $n=14)$ with the most common and concerning incidental findings being horseshoe kidney $(n=1)$ and lung lesion $(n=1)$. The remainder $(n=7)$ were less serious. Of youth with a reportable or incidental finding, 18 had a PCP but only 7 scheduled a follow-up appointment. Seven participants without a PCP were referred to a safety-net clinic for follow-up.

\footnotetext{
*Correspondence: Gabriel.shaibi@asu.edu

${ }^{2}$ Center for Health Promotion and Disease Prevention, Edson College

of Nursing and Health Innovation, Arizona State University, 500 N. 3rd St,

Phoenix, AZ 85004, USA

Full list of author information is available at the end of the article
}

(C) The Author(s) 2021. Open Access This article is licensed under a Creative Commons Attribution 4.0 International License, which permits use, sharing, adaptation, distribution and reproduction in any medium or format, as long as you give appropriate credit to the original author(s) and the source, provide a link to the Creative Commons licence, and indicate if changes were made. The images or other third party material in this article are included in the article's Creative Commons licence, unless indicated otherwise in a credit line to the material. If material is not included in the article's Creative Commons licence and your intended use is not permitted by statutory regulation or exceeds the permitted use, you will need to obtain permission directly from the copyright holder. To view a copy of this licence, visit http://creativecommons.org/licenses/by/4.0/. The Creative Commons Public Domain Dedication waiver (http://creativeco mmons.org/publicdomain/zero/1.0/) applies to the data made available in this article, unless otherwise stated in a credit line to the data. 
Conclusions: With the increased utilization of high-resolution imaging in pediatric research, additional standardization is needed on what, when, and how to return incidental and reportable findings to participants, particularly among historically underrepresented populations that may be underserved in the community.

Trial registration: Preventing Diabetes in Latino Youth, NCT02615353

\section{Background}

Disclosing research results to study participants remains controversial as researchers must balance the ethical obligation of the participant's right to know with the uncertainty of the benefit or risk of knowing such information [1]. Incidental findings (IFs) add further disclosure challenges for researchers as they often represent a discovery unrelated to the purpose of the study but may be valid and medically actionable $[2,3]$. IFs are common with the application of state-of-the-art imaging techniques in clinical research [4], yet there is no consensus on a systematic process for when, how, and to whom IFs should be communicated back to participants. Governing bodies do not require or prohibit the return of IFs to participants but state that investigators should inform participants when medical care is needed for conditions or illnesses unrelated to the study or the disease being studied $[2,3,5,6]$. However, what to do with this information, and how to effectively communicate it, especially for the non-clinician researcher, underscores the importance of collaboration between researchers and practitioners [6] that has implications that span medicine, ethics, law, and public health.

Communication of IFs may be further complicated among underserved and otherwise underrepresented pediatric populations who experience a disproportionate burden of disease due to social determinants of health $[7,8]$. For example, an IF that warrants follow up care in low-income research participants may present additional challenges due to factors such as limited access to primary and specialty care [9-14], challenges navigating the healthcare system [15-17], and/or low health literacy [18-20]. As efforts are made to increase the diversity of clinical trial populations by enrolling underrepresented and underserved groups [21], it is critical for researchers to consider contextual and structural factors that are operational within socially disadvantaged populations so that research participation does not exacerbate existing heath disparities.

There is an extensive body of literature discussing IF identification during imaging research studies among adults [22-24]. In contrast, this topic has only recently received attention in children with most research focused on brain imaging studies [25-28]. High resolution imaging techniques to measure ectopic fat depots among youth has gained traction to better understand the current epidemic of pediatric obesity and related conditions [29-31]. The increased use of advanced imaging techniques in pediatric obesity research coupled with the existing disparities in obesity and related conditions make it likely that IFs will be identified in participants that may experience barriers to following up on such findings. However, there are no published pathways or protocols for handling IFs in the pediatric obesity research literature.

Therefore, the aims of the current report are: 1) describe the process for identifying and returning findings from a research MRI to low-income Latino children and families participating in a randomized clinical trial with an imaging component, 2) characterize the number, type, and potential implications of findings on follow-up management, and 3) present key lessons learned throughout the process.

\section{Methods \\ Subjects}

As part of the Preventing Diabetes in Latino Youth study, a randomized controlled trial evaluating the efficacy of a lifestyle intervention for the prevention of type 2 diabetes mellitus (T2D) among Latino youth with obesity and prediabetes, youth and their families were offered the opportunity to undergo a research MRI for assessment of regional fat distribution including subcutaneous abdominal adipose tissue, visceral adipose tissue, pancreatic fat, and liver fat. The current report describes the process for identifying and communicating findings discovered during the research MRI along with the number, type, and follow-up recommendations to families.

Details of the Preventing Diabetes in Latino Youth study design and methodology have been previously published [32]. Participants were enrolled from a variety of community and clinical settings [33] and randomized to either six-month lifestyle intervention or a usual care control group. Inclusion criteria were youth aged 12-16years old at enrollment, who self-identified as Latino, with obesity (BMI $\geq 95$ th percentile for age and sex or a BMI $\geq 30 \mathrm{~kg} / \mathrm{m}^{2}$ ), and prediabetes (hemoglobin A1c between 5.7-6.4\%, fasting glucose between 100 and $125 \mathrm{mg} / \mathrm{dL}$, or 2 -h glucose between 120 and $199 \mathrm{mg} /$ dL). Figure 1 summarizes youth screened, excluded, and included for the parent study. This study was approved by both Arizona State University's and Phoenix Children's 


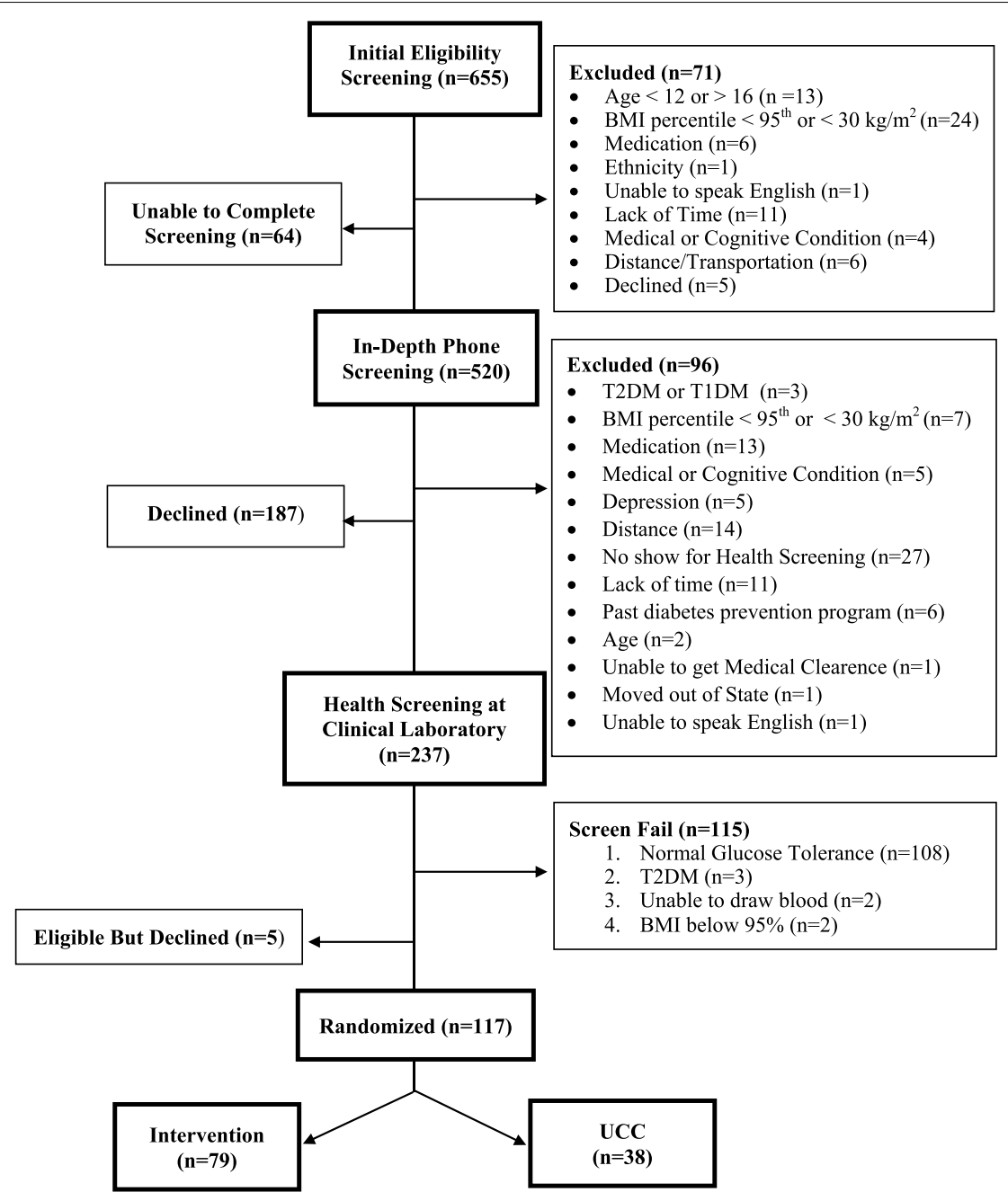

Abbreviations: BMI=Body mass index; T1DM=Type 1 diabetes mellitus; T2DM=Type 2 diabetes mellitus; UCC=Usual care control

Fig. 1 Preventing Diabetes in Latino Youth CONSORT Flow Diagram

Hospital Institutional Review Boards. Informed consent was obtained from a parent/guardian and assent was obtained from all youth prior to undergoing research related MRIs. During the consent process, the youth and parent/legally authorized representative were informed of the potential discovery of unrelated incidental or reportable findings and if warranted would be notified of any such finding.

\section{MR imaging acquisition}

All MRI studies were acquired on the same $3 \mathrm{~T}$ scanner (Philips Ingenia $3 \mathrm{~T}$ MRI), with a 44-channel posterior table coil, located in the Department of Radiology at Phoenix Children's Hospital. All scans were conducted by a board-certified MR imaging technologist by use of a standard protocol. A single-breathhold 6-echo acquisition with a 7 peak fat modeling, and T2* correction to create $3 \mathrm{D}$ fat fraction maps. Parameters used were TE:12/16/20/24ms; TR:7.68 ms; T1, $18 \mathrm{~ms}$; FOV, $400 \times 400 \mathrm{~mm}$; effective voxel resolution, $1 \mathrm{X} 1 \mathrm{X} 1 \mathrm{~mm}^{3}$; scanning time, $5 \mathrm{~min}$.

\section{Development of institutional pathway for identification and reporting of incidental findings}

An iterative process that engaged hospital administration, research compliance, radiology, and the research team was used to develop a pathway for identifying and reporting findings to participants and families. Figure 2 provides a timeline of major events, meetings, and 


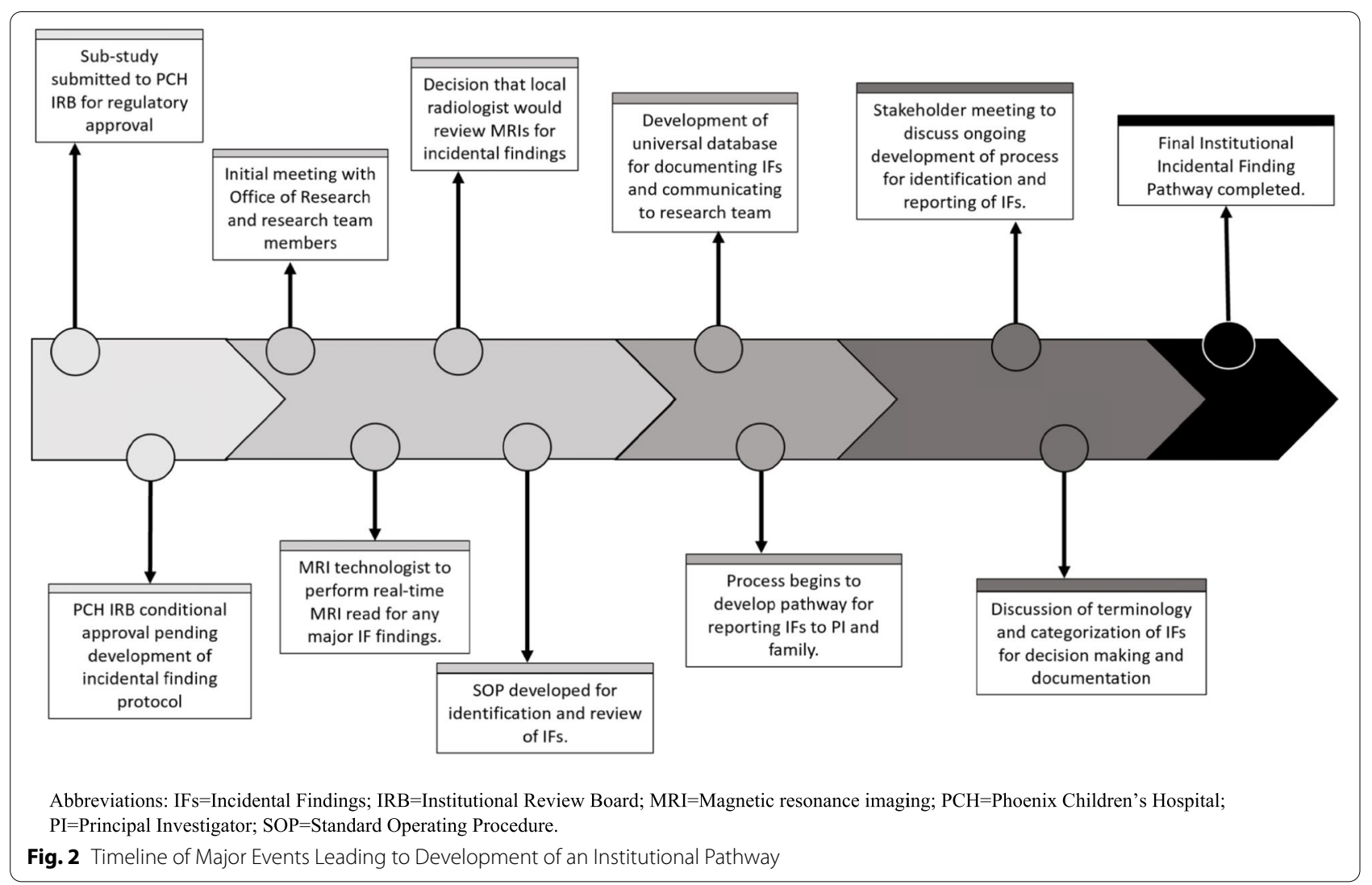

decisions that contributed to the development of the final pathway.

\section{Assessment and classification of incidental findings}

All MR images were reviewed by a board-certified pediatric radiologist who communicated findings to the project physician (i.e., a pediatric endocrinologist) for additional consideration. The project physician evaluated each finding to determine reportability and deemed findings incidental if they were medically important, clinically actionable, and beyond the scope of the study; and reportable if they were medically important and clinically actionable.

Because the research was conducted at a tertiary care center in a children's hospital, several pediatric sub-specialists were available for consultation in the determination of whether a finding was reportable and, if so, what additional clinical actions may be recommended. Once deemed clinically actionable, the project physician communicated the finding and provided recommendations for follow-up care to the participant and their parent / legally authorized representative(s) via telephone and in writing. Whenever appropriate, written communication was translated into Spanish and verbal communication was performed with Spanish interpreters or Spanish speaking physicians. Since youth were recruited from a variety of settings, findings were only discussed with the participant's primary care provider (PCP) if the family provided consent for a release of records. If the family provided consent, the project physician provided the PCP with both verbal and written communication regarding the finding including any recommended next steps. Participants without insurance were referred to a free community health clinic where the medical director, a PCP, agreed to receive referrals and help coordinate follow-up as necessary.

\section{Results}

\section{Participant demographics}

Table 1 summarizes demographic data, including anthropometric and socioeconomic data, of participants. Parental education level varied; however, the majority of parents had a high school education or less $(71 \%, n=61)$. Almost $80 \%(n=68)$ of participants were covered under the Arizona Medicaid Program for health insurance and $51 \%(n=44)$ participated in a federal food assistance program including Supplemental Nutrition Assistance Program (SNAP), SNAP for Women, Infants, and Children (WIC), or a combination of both. 
Table 1 Demographic, Anthropometric, and Socioeconomic Characteristic of Participants $(n=86)$ in Imaging Substudy

\begin{tabular}{|c|c|}
\hline Variable & Mean \pm SD or $\%(n)$ \\
\hline Age (years), mean $\pm S D$ & $13.6 \pm 1.4$ \\
\hline Gender, \% male (n) & $60.5 \%(52)$ \\
\hline $\mathrm{BMI}\left(\mathrm{kg} / \mathrm{m}^{2}\right)$, mean $\pm \mathrm{SD}$ & $34.1 \pm 5.4$ \\
\hline BMI Percentile (\%), mean \pm SD & $98.5 \pm 1.2$ \\
\hline \multicolumn{2}{|l|}{ Recruitment Site, \% (n) } \\
\hline Clinical & $51.2 \%(44)$ \\
\hline Community & $17.4 \%(15)$ \\
\hline Media & $23.3 \%(20)$ \\
\hline Word of Mouth & $8.1 \%(7)$ \\
\hline \multicolumn{2}{|l|}{ Parent Highest Education Level, \% (n) } \\
\hline Less than 6th grade & $4.7 \%(4)$ \\
\hline Completed elementary school (6th grade) & $22.1 \%(19)$ \\
\hline Completed middle school (9th grade) & $25.6 \%(22)$ \\
\hline Completed high school (12th grade) & $18.6 \%(16)$ \\
\hline Completed technical school & $8.1 \%(7)$ \\
\hline Some college & $10.6 \%(9)$ \\
\hline College graduate or higher & $7.0 \%(6)$ \\
\hline \multicolumn{2}{|l|}{ Parent Income Level, \% (n) ${ }^{\mathrm{a}}$} \\
\hline$\$ 0$ to $\$ 500$ per month & $2.3 \%(2)$ \\
\hline$\$ 501$ to $\$ 1000$ per month & $8.1 \%(7)$ \\
\hline$\$ 1001$ to $\$ 2000$ per month & $10.5 \%(9)$ \\
\hline$\$ 2001$ to $\$ 3000$ per month & $8.1 \%(7)$ \\
\hline$\$ 3001$ to $\$ 4000$ per month & $1.2 \%(1)$ \\
\hline Household size (total \# of people), mean \pm SD & $5.3 \pm 1.7$ \\
\hline \multicolumn{2}{|l|}{ Government Assistance, $\%$ yes ( $\mathrm{n}$ ) } \\
\hline WIC & $18.6 \%(16)$ \\
\hline State Medicaid Program & $79.1 \%(68)$ \\
\hline Food Stamps (Nutrition Assistance Program) & $40.7 \%(35)$ \\
\hline Section 8 Voucher & $1.2 \%(1)$ \\
\hline Disability Insurance & $7.0 \%(6)$ \\
\hline Other type of government assistance & $1.2 \%(1)$ \\
\hline
\end{tabular}

Abbreviations: $\mathrm{BMI}=$ Body mass index; $\mathrm{SD}=$ Standard deviation; $\mathrm{WIC}=$ Special Supplemental Nutrition Program for Women, Infant, and Children

a Parental income level had 60 individuals indicating do not know or refused to answer

\section{Institutional pathway for identification and reporting of incidental findings}

The iterative process outlined in Fig. 2 resulted in the development and implementation of an institutional pathway (Fig. 3) for the identification, categorization, and communication of findings discovered during a research MRI.

\section{Incidental finding prevalence}

MRIs were performed on 86 youth at baseline and 53 post-intervention yielding a total of 139 images. From these images, 31 findings in 25 participants were identified by the radiologist. Twenty-three of the 31 findings (75\%) were deemed incidental or reportable by the project physician and communicated to youth and their families. Table 2 provides a summary of the findings among the study cohort along with national prevalence rates, clinical recommendations, and potential implications. The only reportable finding was severely elevated liver fat $(n=14)$ which was considered reportable if found to be $\geq 10 \%$. The most concerning IFs were horseshoe kidney $(\mathrm{n}=1)$ and a lung lesion $(\mathrm{n}=1)$ while the remainder $(n=7)$ were considered less serious.

\section{Communication of IF to youth, family, and PCP}

Of the 25 participants found to have either an incidental or reportable finding, 18 (72\%) had a PCP but only seven (29\%) followed-up with their PCP to discuss the IF. Participants that did not have a PCP $(n=7)$ were referred to the community clinic that provides care for uninsured patients.

\section{Discussion}

The percentage of youth with MRI findings in our study (29\%) was higher than previous studies with a range of $11-27 \%[25,26,28,40,41]$. In addition, the majority (75\%) of findings in the current study met the internal threshold for reportability with 39\% deemed incidental, which was substantially greater than previous reports (range: $0.5-36 \%$ ) [25, 26, 28, 40, 41]. There were key lessons learned throughout the process that aided the development and implementation of the institutional pathway with the key takeaway being the need to better understand and assess the benefits as well as the potential harms associated with communicating research MRI findings. This is of particular importance among underrepresented populations where other challenges emerge such as low health literacy and barriers to follow-up care. By providing a detailed description of the process implemented at our institution, we hope to provide valuable information needed for building a broader consensus and unified management protocol for reporting IFs while considering social determinants of health.

Treatment protocols for the management of IFs for nondiagnostic MRI have been previously published among adult populations [23] or neuro-imaging studies [24-26, 28, 40, 41]. The published protocols for the identification, classification, and communication of IFs among pediatric populations [28, 40, 42], highlight the importance of explaining risks and benefits of IFs during the consent process, incorporation of multiple expert opinions in documenting and categorization of IFs, and the communication of IFs to participants [28, 40]. However, previously published pediatric protocols for IFs 


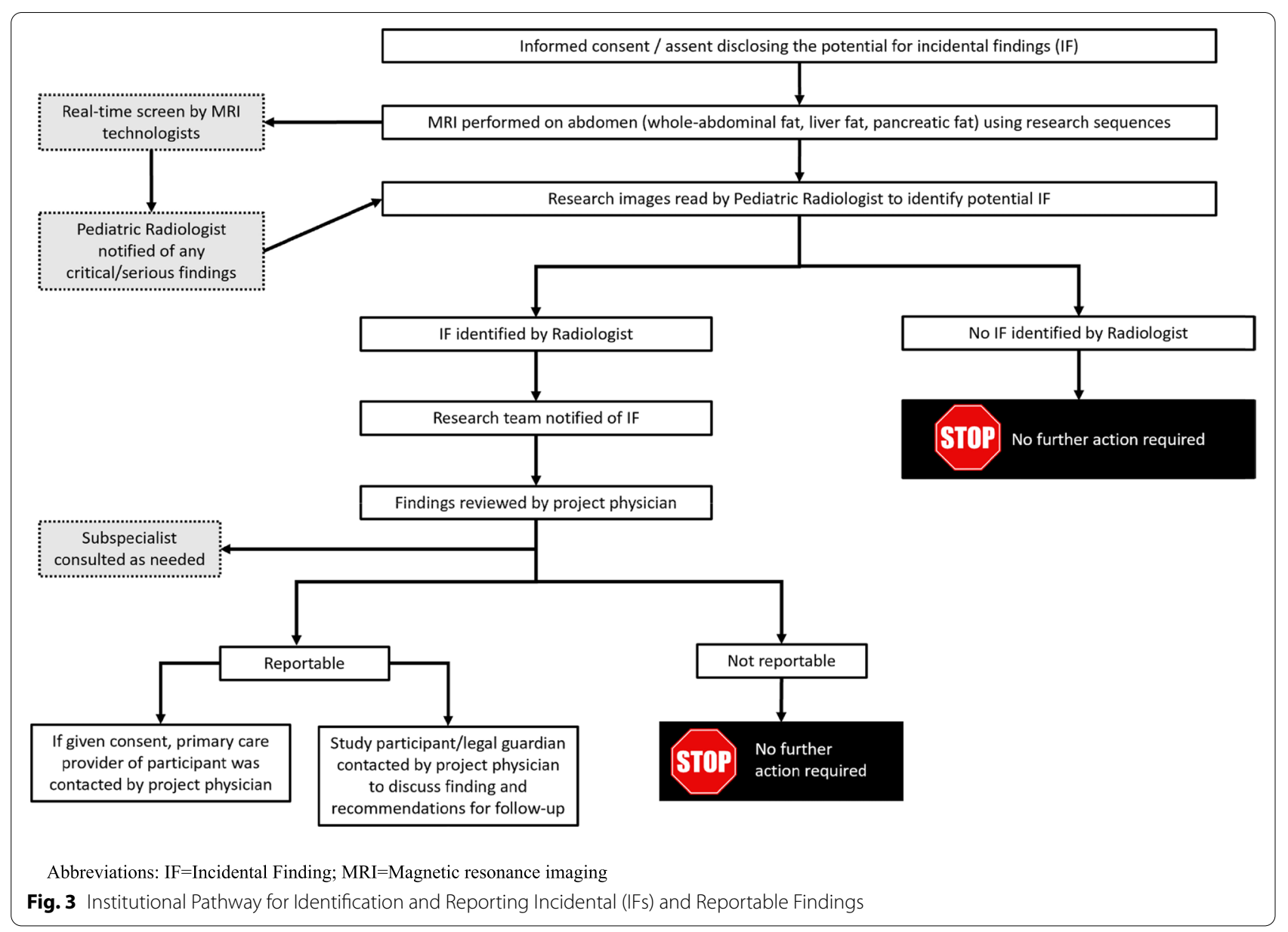

were established for brain MRIs in otherwise healthy children [28,40], which is in contrast to the current study where youth with obesity and prediabetes underwent an abdominal MRI. Not surprisingly, the likelihood of discovering an IF differs by region of interest [23, 43, 44 ] and with the use of more sophisticated imaging platforms [25]. Previous studies have reported an IF prevalence of $36 \%$ among adults who underwent a whole-body research MRI [23]; unfortunately, there are no published pediatric prevalence rates for whole-body or abdominal MRIs performed during pediatric research. However, a recent systematic review of pediatric whole-body MRI scans for diagnostic purposes [43] found only one study which reported IFs prevalence of $96 \%(n=55)$ [44]. The relatively high prevalence of findings in the current study may be largely driven by the inclusion of fatty liver as a reportable finding. Given that liver fat was an a priori outcome of interest in the parent trial and Latino youth with obesity are at increased risk for fatty liver [45-47], it was more appropriate to consider elevated liver fat as a reportable finding rather and an IF. Discussions with the IRB and pediatric hepatologists at our institution led to the decision to report elevated liver fat to families. However, rather than using the current clinical recommendation of $>5 \%$ liver fat [48], we applied a more conservative threshold of $>10 \%$ at 6 -months as reportable. The rationale being that the intervention under investigation (lifestyle behavior change) is considered a first line treatment for pediatric fatty liver disease but in the absence of improvement, and at a level two-fold greater than normal, warrants additional consideration and work-up. If we omit fatty liver as a reportable, the cumulative prevalence for both reportable and incidental findings in the current study is $29 \%$. Definitions notwithstanding, the enhanced utilization of new technologies increase the likelihood of primary and IF discovery that warrant follow-up; therefore, additional guidance and standardization on how best to handle IF outside of clinical care is needed.

In deciding whether to deem a finding reportable, the research team must make a subjective decision in determining the clinical significance and actionability of a finding. The research team needs to first weigh the importance of an IF along a spectrum of 
Table 2 Reportable and Incidental Findings for Study Cohort with National Prevalence, Recommendations, and Potential Implications of Condition

\begin{tabular}{|c|c|c|c|c|}
\hline Condition & Study Proportion & Population Prevalence & Recommendations & $\begin{array}{l}\text { Implication and Differential } \\
\text { Diagnosis }\end{array}$ \\
\hline Cholelithiasis & $2.3 \%(2)$ & $1.9-4.0 \%[34]^{*}$ & $\begin{array}{l}\text { - Evaluation by PCP. } \\
\text { - If child develops abdominal pain, } \\
\text { vomiting, or fever, please go to the ED. }\end{array}$ & $\begin{array}{l}\text { - No evidence of inflammation most } \\
\text { likely indicates no acute health prob- } \\
\text { lems. }\end{array}$ \\
\hline Horseshoe kidney & $1.2 \%(1)$ & $0.16 \%[35]^{*}$ & $\begin{array}{l}\text { - Evaluation by PCP. } \\
\text { - Referral to Pediatric Nephrologist. }\end{array}$ & $\begin{array}{l}\text { - Increased risk for hydronephrosis, } \\
\text { urinary obstruction, renal calculi, and } \\
\text { urinary tract infections. }\end{array}$ \\
\hline Left lung lesion & $1.2 \%(1)$ & Not applicable & $\begin{array}{l}\text { - Evaluation by PCP. } \\
\text { - Referral to Pediatric Pulmonologist. }\end{array}$ & $\begin{array}{l}\text { - Possible causes include pneumonia, } \\
\text { granulomatous disease, and metastatic } \\
\text { cancer. }\end{array}$ \\
\hline Hepatic cyst & $1.2 \%(1)$ & $2.5 \%[36]$ & $\begin{array}{l}\text { - Evaluation by PCP. } \\
\text { - Referral to Pediatric Gastroenterolo- } \\
\text { gist. } \\
\text { - Liver ultrasound. }\end{array}$ & $\begin{array}{l}\text { - Most likely benign, however other pos- } \\
\text { sible causes include neoplasm, abscess, } \\
\text { and hemangioma. }\end{array}$ \\
\hline Renal cyst & $2.3 \%(2)$ & $\begin{array}{l}0.1-0.25 \%(A D P K D)[37]^{*} \\
0.003-0.01 \%(A R P K D)[37]^{*}\end{array}$ & $\begin{array}{l}\text { - Evaluation by PCP. } \\
\text { - Referral to Pediatric Nephrologist. } \\
\text { - Renal ultrasound. }\end{array}$ & $\begin{array}{l}\text { - Most likely benign, however may rep- } \\
\text { resent congenital or acquired polycystic } \\
\text { kidney disease. }\end{array}$ \\
\hline Ovarian cyst(s) & $2.3 \%(2)$ & $6-20 \%[38]$ & • Evaluation by PCP. & $\begin{array}{l}\text { - Most likely benign and will resolve } \\
\text { without intervention. } \\
\text { - May be suggestive of polycystic ovar- } \\
\text { ian syndrome. }\end{array}$ \\
\hline $\begin{array}{l}\text { Severely elevated } \\
\text { liver fat }>10 \%^{a, b}\end{array}$ & $16.3 \%(14)$ & $9.6 \%[39]^{*}$ & $\begin{array}{l}\text { - Evaluation by PCP. } \\
\text { - Referral to Pediatric Gastroenterolo- } \\
\text { gist. }\end{array}$ & $\begin{array}{l}\text { - Most likely etiology is nonalcoholic } \\
\text { fatty liver disease, however, cannot rule } \\
\text { out other potential causes of liver fat. }\end{array}$ \\
\hline
\end{tabular}

Abbreviations: ADPKD = Autosomal Dominant Polycystic Kidney Disease; ARPKD = Autosomal Recessive Polycystic Kidney Disease; ED = Emergency Department; $\mathrm{PCP}=$ Primary Care Physician

*Asterisk indicates the population prevalence is specific to pediatrics

a This is based on prevalence of non-alcoholic fatty liver disease (NAFLD) as defined by liver fat > 5.5\%. NAFLD prevalence increases among Hispanic youth (11.8\%) and youth with obesity (38\%)

b Severely elevated liver fat was deemed a reportable finding based upon discussions with the IRB

clinical significance [49]. However, the MRI performed for research purposes in many cases cannot determine where the IF falls on the spectrum. Even after deeming a finding clinically relevant, the research team is challenged with effectively communicating the medical importance of an IF to multiple individuals (i.e., youth, family, and PCP) when its clinical significance is unclear. This is further complicated when working with participants from a low-income, health disparate population $[9,10]$.

Differences in culture, language, health literacy, and access to care have the potential to magnify the inherent challenges faced in communicating the clinical significance of findings. Although we did not assess health literacy, the majority $(64 \%, n=78)$ of the primarily Spanish-speaking parents in the study completed at least 9th grade. Parental health literacy is intimately tied with child health [50]; however, research that prioritizes underserved adolescent populations typically encounter youth that are of higher health literacy than their parents $[51,52]$, or have the technological know-how to seek out additional information [53]. Therefore, it stands to reason that returning IFs in populations with low health literacy warrants additional considerations to further minimize undue worry and confusion.

Research that prioritizes vulnerable and underserved populations with limited access to care may amplify both the benefit and harm associated with the discovery and communication of IFs. Understanding that the communication of IFs may lead to additional costs and followup care, but most importantly, unnecessary anxiety and stress needs not only be considered but also adequately assessed in imaging research. With the intention to diversify study populations within clinical research trials [54], it may be warranted to allocate additional funds or resources for care beyond the scope of the study in order to prevent greater health disparities $[9,10]$ in an already at-risk population. Social determinants of health exacerbate equitable access to care in an already fragmented healthcare system. As researchers we need to challenge ourselves to address not only the complexities of communicating uncertain findings to research participants 
Table 3 Recommendations and Considerations for Addressing Incidental and Reportable Findings in Pediatric Research

\begin{tabular}{ll}
\hline Area. & Recommendation \\
\hline Funding agencies & $\begin{array}{l}\text { Allocate fund use when an incidental finding is discovered to assist in provision of follow-up care, particularly among under- } \\
\text { served populations that lack access to specialty care and/or insurance. }\end{array}$ \\
Scientific Organizations & $\begin{array}{l}\text { Establish best practices and scientific statements to guide pediatric researchers who encounter incidental findings during } \\
\text { investigations } \\
\text { Informed Consent }\end{array}$ \\
$\begin{array}{l}\text { Clearly explain the nondiagnostic intent of the MRI as well as the possibility of discovering unrelated, unintended but poten- } \\
\text { tially clinically relevant findings. }\end{array}$ \\
$\begin{array}{l}\text { Track the impact of incidental finding communication to the participant and their family, including additional clinical visits } \\
\text { and diagnostic tests, to better assess the financial and time-related costs and potential health benefits. }\end{array}$ \\
$\begin{array}{l}\text { Develop a process for how incidental findings will be identified and communicated among members of the research team as } \\
\text { well as to families and primary care providers. }\end{array}$
\end{tabular}

but also how clinical research can address social determinants of health.

There were several lessons learned during the process of developing and implementing an institutional pathway for the identification and communication of incidental and reportable findings during nondiagnostic abdominal MRIs. These lessons learned have been compiled into recommendations and considerations for addressing findings discovered during pediatric research (Table 3). Through the entire process, the most prominent takeaway was the need to better understand the risk-to-benefit ratio of reporting findings to ensure potential repercussions are minimized for youth, families, and the PCP. The communication of findings must include a benefit [55] such as early identification of a clinically relevant health condition that leads to early prevention and treatment or equipping research participants with new information that enables them to make more informed decisions $[1$, 56]. These possible benefits must be weighed against the potential cost of unnecessary medical visits, diagnostic studies, and treatments; as well as the anxiety induced for participants and their medical providers due to the incomplete, unclear significance of a given finding.

Our study had several limitations. First, all youth were of Latino ethnicity which limits the generalizability to other populations. Second, we did not assess the health literacy of the youth and their parent/guardians which may impact the effectiveness and cost associated with communicating uncertain and incomplete medical information. Third, the study was not designed to prospectively evaluate the impact of IFs on future outcomes and participants were not randomized based upon receiving or not receiving findings. Lastly, we did not attempt to quantify the cost to the families due to the IF or the long-term implications, which represents a gap in the literature. The ability to accurately assess the risk-tobenefit ratio of communicating IF includes evaluation of the financial cost, time and productivity lost, and anxiety that results from this process. This is even more important among populations with health disparities where differences in cultural values, language barriers, and other social determinants of health increase the possibility of miscommunication leading to greater confusion and anxiety. Despite these limitations, there were several strengths to our study including that one pediatric radiologist read all the images reducing variability in reporting. Additionally, a single high-field scanner with high-resolution imaging was used for all participants providing a benchmark for the prevalence of incidental findings among a homogenous but underrepresented cohort of Latino youth with obesity.

\section{Conclusion}

To our knowledge, this is the first study among a pediatric population that has described prevalence rates and a protocol for reporting incidental and reportable findings discovered during a nondiagnostic abdominal MRI. As clinical trials increasingly use high-field, high-resolution magnets, the establishment of single institution protocols and pathways are important steps towards building broader consensus for handling such findings. Most importantly is the need to adequately weigh the potential benefits with the associated risks of communicating uncertain, incomplete medical information. We hope that our experience will empower other researchers to consider the sociocultural context of study populations when developing protocols and encourage imaging studies to track the financial and psychosocial implications associated with communicating incidental and reportable findings, particularly among underserved and underrepresented populations.

\section{Acknowledgements}

We would like to thank youth and their families for participating in the study. We would also like to thank our community (St. Vincent de Paul and YMCA) and clinical (Phoenix Children's Hospital and Mountain Park Healthcare) partners for their commitment to not only the local community but also to this clinical trial. The authors have no conflicts of interest.

\section{Authors' contributions}

K.B.V. performed the initial analyses, drafted the initial manuscript, and reviewed and revised the manuscript as needed. G.Q.S. and M.L.O. conceptualized and designed the study, coordinated, and supervised data collection, drafted the initial manuscript, and critically reviewed the manuscript for important intellectual content. S.S.B. and J.M. coordinated and supervised 
data collection, and critically reviewed the manuscript for important intellectual content. A.M.V., J.P., and K.O. coordinated and collected data, and critically reviewed the manuscript for important intellectual content. A.P. contributed to initial draft of manuscript and critically reviewed the manuscript for important intellectual content. M.S., L.S., and R.B.R. critically reviewed the manuscript for important intellectual content. All authors approved the final manuscript as submitted and agree to be accountable for all aspects of the work.

\section{Funding}

This work was supported by a grant from the National Institute of Diabetes and Digestive and Kidney Diseases (R01DK107579). Mr. Peña is supported by a training grant from National Institute of Diabetes and Digestive and Kidney Diseases (F31DK125037). The NIH had no role in the design or conduct of the study. De-identified data is available upon request.

\section{Availability of data and materials}

The datasets used and/or analyzed during the current study are available from the corresponding author on reasonable request.

\section{Declarations}

\section{Ethics approval and consent to participate}

The Arizona State University's (STUDY00003735) and Phoenix Children's Hospital (\#16-008) Institutional Review Boards approved all study protocols. This study was performed in accordance with relevant guidelines and regulations (i.e., Declaration of Helsinki). The study was conducted Informed consent was obtained from a parent/guardian and assent was obtained from all youth prior to undergoing research related MRIs. During the consent process, the youth and parent/legally authorized representative were informed of the potential discovery of unrelated incidental or reportable findings and if warranted would be notified of any such finding.

\section{Consent for publication}

Not applicable.

\section{Competing interests}

The authors declare that they have no competing interests.

\section{Author details}

${ }^{1}$ College of Graduate Studies, Midwestern University, Glendale, AZ, USA. ${ }^{2}$ Center for Health Promotion and Disease Prevention, Edson College of Nursing and Health Innovation, Arizona State University, 500 N. 3rd St, Phoenix, AZ 85004, USA. ${ }^{3}$ Division of Pediatric Endocrinology and Diabetes, Phoenix Children's Hospital, Phoenix, AZ, USA. ${ }^{4}$ Department of Radiology, Phoenix Children's Hospital, Phoenix, AZ, USA. ${ }^{5}$ Division of Gastroenterology, Phoenix Children's Hospital, Phoenix, AZ, USA. ${ }^{6}$ Department of Child Health, University of Arizona College of Medicine, Phoenix, AZ, USA. ${ }^{7}$ Office of Research, Phoenix Children's Hospital, Phoenix, AZ, USA. ${ }^{8}$ Division of Pediatric Critical Care Medicine, Phoenix Children's Hospital, Phoenix, AZ, USA. ${ }^{9}$ Southwest Interdisciplinary Research Center, Arizona State University, Phoenix, AZ, USA.

Received: 24 June 2021 Accepted: 27 October 2021

Published online: 05 December 2021

\section{References}

1. Wong CA, Hernandez AF, Califf RM. Return of research results to study participants uncharted and untested. JAMA. 2018;320:435-6.

2. Office for Human Research Protections. Attachment F- Recommendations on Reporting Incidental Findings.

3. Presidential Commission for the Study of Bioethical Issues. ANTICIPATE and COMMUNICATE: Ethical Management of Incidental and Secondary Findings in the Clinical, Research, and Direct-to-Consumer Contexts. Washington, D.C.; 2013.

4. Li Y, Thompson WK, Reuter C, Nillo R, Jernigan T, Dale A, et al. Rates of incidental findings in brain magnetic resonance imaging in children. JAMA Neurol. 2021;78:578-87.
5. Meacham MC, Starks H, Burke W, Edwards K. Researcher perspectives on disclosure of incidental findings in genetic research. J Empir Res Hum Res Ethics. 2010;5:31-41.

6. Wolf SM. Introduction: the challenge of incidental findings. J Law Med Ethics. 2008;36:216-8. https://doi.org/10.1038/jid.2014.371.

7. Cheng TL, Emmanuel MA, Levy DJ, Jenkins RR. Child health disparities: what can a clinician do? Pediatrics. 2015;136:962-8.

8. Butler AM. Social determinants of health and racial/ethnic disparities in type 2 diabetes in youth. Curr Diab Rep. 2017;17:2-5.

9. Mackay D. Returning incidental findings in low-resource settings: a case of rescue? Hast Cent Rep. 2018;48:28-30.

10. Sullivan HK, Berkman BE. Incidental findings in low-resource settings. Hast Cent Rep. 2018;48:20-8.

11. Merritt MW, Taylor HA, Mullany LC. Ancillary care in communitybased public health intervention research. Am J Public Health. 2010;100:211-6.

12. Pérez-Escamilla R. Health care access among Latinos: implications for social and health care reforms. J Hispanic High Educ. 2010;9:43-60.

13. Flores $G$, Vega LR. Barriers to health care access for Latino children: a review. Fam Med. 1998:30:196-205.

14. Cyr ME, Etchin AG, Guthrie BJ, Benneyan JC. Access to specialty healthcare in urban versus rural US populations: a systematic literature review. BMC Health Serv Res. 2019;19:1-17.

15. Sanchez-Birkhead AC, Kennedy HP, Callister LC, Miyamoto TP. Navigating a new health culture: experiences of immigrant hispanic women. J Immigr Minor Health. 2011;13:1168-74.

16. Bade E, Evertsen J, Smiley S, Banerjee I. Navigating the health care system: a view from the urban medically underserved. Wis Med J. 2008;107:374-9.

17. Madden EF. Cultural health capital on the margins: cultural resources for navigating healthcare in communities with limited access. Soc Sci Med. 2015;133:145-52. https://doi.org/10.1016/j.socscimed.2015.04.006.

18. Vega WA, Rodriguez MA, Gruskin E. Health disparities in the latino population. Epidemiol Rev. 2009;31:99-112.

19. Marciano L, Camerini AL, Schulz PJ. The role of health literacy in diabetes knowledge, self-care, and glycemic control: a Meta-analysis. J Gen Intern Med. 2019;34:1007-17.

20. Parker RM, Ratzan SC, Lurie N. Health literacy: a policy challenge for advancing high-quality health care. Health Aff. 2003;22:147-53.

21. Clark LT, Watkins L, Piña IL, Elmer M, Akinboboye O, Gorham M, et al. Increasing diversity in clinical trials: overcoming critical barriers. Curr Probl Cardiol. 2019:44:148-72.

22. Gibson LM, Paul L, Chappell FM, Macleod M, Whiteley WN, Salman RAS, et al. Potentially serious incidental findings on brain and body magnetic resonance imaging of apparently asymptomatic adults: systematic review and meta-analysis. BMJ. 2018;363.

23. Hegenscheid K, Seipel R, Puls R. Potentially relevant incidental findings on research whole-body MRI in the general adult population : frequencies and management 2013;:816-826.

24. Rangel EK. The Management of Incidental Findings in Neuro-imaging research. Framework Recommendations. 2010

25. Gur RE, Kaltman D, Melhem ER, Ruparel K, Prabhakaran K, Riley M, et al. Incidental findings in youths volunteering for brain MRI research. Am J Neuroradiol. 2013;34:2021-5.

26. Jansen $P R$, Dremmen $M$, van den Berg A. Incidental findings on brain imaging in the general pediatric population. N Engl J Med. 2017;377:19-21.

27. Anastasova V, Mahalatchimy A, Rial-Sebbag E, Antó Boqué JM, Keil T, Sunyer J, et al. Communication of results and disclosure of incidental findings in longitudinal paediatric research. Pediatr Allergy Immunol. 2013;24:389-94.

28. Kaiser D, Leach J, Vannest J, Schapiro M, Holland S. Unanticipated findings in pediatric neuroimaging research: prevalence of abnormalities and process for reporting and clinical follow-up. Brain Imaging Behav. 2015;9:32-42.

29. Kovanlikaya A, Mittelman SD, Ward A, Geffner ME, Dorey F, Gilsanz V. Obesity and fat quantification in lean tissues using three-point Dixon MR imaging. Pediatr Radiol. 2005;35:601-7.

30. Samara A, Ventura EE, Alfadda AA, Goran MI. Use of MRI and CT for fat imaging in children and youth: what have we learned about obesity, fat distribution and metabolic disease risk? Obes Rev. 2012;13:723-32. 
31. Pacifico L, di Martino M, Catalano C, Panebianco V, Bezzi M, Anania C, et al. T1-weighted dual-echo MRI for fat quantification in pediatric nonalcoholic fatty liver disease. World J Gastroenterol. 2011;17:3012-9.

32. Soltero EG, Konopken YP, Olson ML, Keller CS, Castro FG, Williams AN, et al. Preventing diabetes in obese Latino youth with prediabetes: a study protocol for a randomized controlled trial. BMC Public Health. 2017;17:1-12.

33. Vander Wyst KB, Olson ML, Hooker E, Soltero EG, Konopken YP, Keller CS, et al. Yields and costs of recruitment methods with participant phenotypic characteristics for a diabetes prevention research study in an underrepresented pediatric population. Trials. 2020;21:1-11.

34. Sarrami M, Ridley W, Nightingale S, Wright T, Kumar R. Adolescent gallstones - need for early intervention in symptomatic idiopathic gallstones. Pediatr Surg Int. 2019;35:569-74. https://doi.org/10.1007/ s00383-019-04461-w.

35. Weizer AZ, Silverstein AD, Auge BK, Delvecchio FC, Raj G, Albala DM, et al. Determining the incidence of horseshoe kidney from radiographic data at a single institution. J Urol. 2003;170:1722-6.

36. Borhani AA, Wiant A, Heller MT. Cystic hepatic lesions: a review and an algorithmic approach. Am J Roentgenol. 2014;203:1192-204.

37. Kwatra S, Krishnappa V, Mhanna C, Murray T, Novak R, Sethi SK, et al. Cystic diseases of childhood: a review. Urology. 2017;110:184-91. https:// doi.org/10.1016/j.urology.2017.07.040.

38. Escobar-Morreale HF. Polycystic ovary syndrome: definition, aetiology, diagnosis and treatment. Nat Rev Endocrinol. 2018;14:270-84.

39. Schwimmer JB, Deutsch R, Kahen T, Lavine JE, Stanley C, Behling C. Prevalence of fatty liver in children and adolescents. Pediatrics. 2006;1 18:1388-93.

40. Seki A, Uchiyama H, Fukushi T, Sakura O, Tatsuya K. Incidental findings of brain magnetic resonance imaging study in a pediatric cohort in Japan and recommendation for a model management protocol. J Epidemiol. 2010;20(SUPPL.2):498-504.

41. Kim BS, Illes J, Kaplan RT, Reiss A, Atlas SW. Incidental findings on pediatric MR images of the brain. Am J Neuroradiol. 2002;23:1674-7.

42. Pietro NC Di, Illes J. Disclosing Incidental Findings in Brain Research : The Rights of Minors in Decision-Making 2013;1013:1009-1013.

43. Zadig P, von Brandis E, Lein RK, Rosendahl K, Avenarius D, Ording Müller LS. Whole-body magnetic resonance imaging in children - how and why? A systematic review. Pediatr Radiol. 2020.

44. Anupindi SA, Bedoya MA, Lindell RB, Rambhatla SJ, Zelley K, Nichols KE, et al. Diagnostic performance of whole-body MRI as a tool for cancer screening in children with genetic cancer-predisposing conditions. Am J Roentgenol. 2015;205:400-8.

45. Welsh JA, Karpen S, Vos MB. Increasing prevalence of nonalcoholic fatty liver disease among United States adolescents, 1988-1994 to 2007-2010. J Pediatr. 2013;162:496-500.e1. https://doi.org/10.1016/j.jpeds.2012.08.043.

46. Betancourt-Garcia MM, Arguelles A, Montes J, Hernandez A, Singh M, Forse RA. Pediatric nonalcoholic fatty liver disease: the rise of a lethal disease among Mexican American Hispanic children. Obes Surg. 2017;27:236-44. https://doi.org/10.1007/s11695-016-2440-5.

47. Pan JJ, Fallon MB. Gender and racial differences in nonalcoholic fatty liver disease. World J Hepatol. 2014;6:274-83.

48. Vos MB, Abrams SH, Barlow SE, Caprio S, Daniels SR, Kohli R, et al. NASPGHAN clinical practice guideline for the diagnosis and treatment of nonalcoholic fatty liver disease in. Children. 2017.

49. Wilfond BS, Carpenter KJ. Incidental findings in pediatric research. J Law Med Ethics. 2008;36:332-40.

50. Sanders LM, Shaw JS, Guez G, Baur C, Rudd R. Health literacy and child health promotion: implications for research, clinical care, and public policy. Pediatrics. 2009;124(SUPPL):3.

51. Guntzviller LM, Jensen JD, Carreno LM. Latino children's ability to interpret in health settings: a parent-child dyadic perspective on child health literacy. Commun Monogr. 2017;84:143-63. https://doi.org/10.1080/ 03637751.2016 .1214871$.

52. Banas JR, Ball JW, Wallis LC, Gershon S. The adolescent health care broker-adolescents interpreting for family members and themselves in health care. J Community Health. 2017:42:739-47.

53. Manganello JA. Health literacy and adolescents: a framework and agenda for future research. Health Educ Res. 2008;23:840-7.
54. Oh SS, Galanter J, Thakur N, Pino-Yanes M, Barcelo NE, White MJ, et al. Diversity in clinical and biomedical research: a promise yet to be fulfilled. PLoS Med. 2015;12:1-9. https://doi.org/10.1371/journal.pmed.1001918.

55. Royal JM, Peterson BS. The risks and benefits of searching for incidental findings in MRI research scans Jason. J Law Med Ethics. 2008;36:301-212. https://doi.org/10.1038/jid.2014.371.

56. Schaefer GO, Savulescu J. The right to know: a revised standard for reporting incidental findings. Hast Cent Rep. 2018;48:22-32.

\section{Publisher's Note}

Springer Nature remains neutral with regard to jurisdictional claims in published maps and institutional affiliations.
Ready to submit your research? Choose BMC and benefit from:

- fast, convenient online submission

- thorough peer review by experienced researchers in your field

- rapid publication on acceptance

- support for research data, including large and complex data types

- gold Open Access which fosters wider collaboration and increased citations

- maximum visibility for your research: over $100 \mathrm{M}$ website views per year

At BMC, research is always in progress.

Learn more biomedcentral.com/submissions 